\title{
Rupture of the normal aortic valve after blunt chest trauma
}

\author{
S. CHI, T. C. BLAIR, AND L. GONZALEZ-LAVIN \\ From the Division of Cardiothoracic Surgery, Michigan State University, East Lansing, Michigan, and \\ Ingham Medical Center, Lansing, Michigan, USA
}

Chi, S., Blair, T. C., and Gonzalez-Lavin, L. (1977). Thorax, 32, 619-622. Rupture of the normal aortic valve after blunt chest trauma. Rupture of the normal aortic valve after blunt trauma to the chest is seen infrequently. With the ever-increasing incidence of car and motorcycle accidents, this injury should be considered during the initial examination of an accident victim. Any patient without a history of heart disease presenting with heart murmurs after severe blunt trauma to the chest should give rise to the suspicion of aortic valve damage. When the diagnosis is proved, aortic valve exploration is necessary. Review of the published cases establishes that valve replacement is the treatment of choice.

Because of its rarity, rupture of the normal aortic valve is not generally considered during the initial assessment of a patient sustaining blunt chest trauma. The case reported here and a review of published cases are intended to emphasise pertinent facts regarding the diagnosis and appropriate treatment of this condition.

\section{Case report}

A 21-year-old white man was involved in a motorcycle accident on 25 August 1975 . He was conscious but slightly disorientated when seen in the emergency room of a local hospital. The patient was admitted for observation, and treatment of skin lacerations and fractures of the right seventh rib and scapula. A chest radiograph showed pulmonary contusion in the left upper lobe. A grade III/VI systolic murmur and grade III/VI diastolic murmur were heard at the second right intercostal space with radiation to the left lower sternal border. While in hospital the patient developed shortness of breath and a productive cough which were attributed to pulmonary contusion. He was discharged home on the fifth day.

Increasing shortness of breath and productive cough persisted, and two days later, after coughing up fresh blood, he was referred to Ingham Medical Center-Michigan State University with a diagnosis of suspected pulmonary embolism, for further investigation and treatment.
Examination on admission showed an acutely ill young man with rapid respirations: blood pressure, $140 / 60 \mathrm{mmHg}$; pulse rate, $110 /$ minute. Grade III/VI systolic and diastolic murmurs were again audible along the left sternal border. Breath sounds were diminished in the left lung. The chest radiograph showed interstitial densities through both lobes of the left lung and, although pulmonary contusion was suspected, early pulmonary oedema could not be ruled out (Fig. 1). An electrocardiogram showed non-specific ST-segment and $\mathrm{T}$-wave changes. Cardiac catheterisation disclosed no intracardiac shunts. Pressure measurements were: pulmonary artery, $39 / 22 \mathrm{mmHg}$; pulmonary capillary wedge, $23 \mathrm{mmHg}$; central aortic, $81 / 42$ $\mathrm{mmHg}$; and left ventricle, $82 / 37 \mathrm{mmHg}$; with an end diastolic pressure in the left ventricle of 48 $\mathrm{mmHg}$. An aortogram demonstrated gross aortic regurgitation.

The patient was operated upon with a diagnosis of severe aortic regurgitation due to non-penetrating traumatic rupture of the aortic valve leaflets. During cardiopulmonary bypass with hypothermic anoxic arrest the right coronary cusp of the aortic valve was found to be partially avulsed from the aortic annulus; the left coronary cusp was completely avulsed as was the intercoronary commissure (Fig. 2). The aortic valve was excised and a size $19 \mathrm{~mm}$ porcine xenograft valve ${ }^{1}$ was in-

${ }^{1}$ Hancock Laboratories, Inc, Anaheim, California, USA 


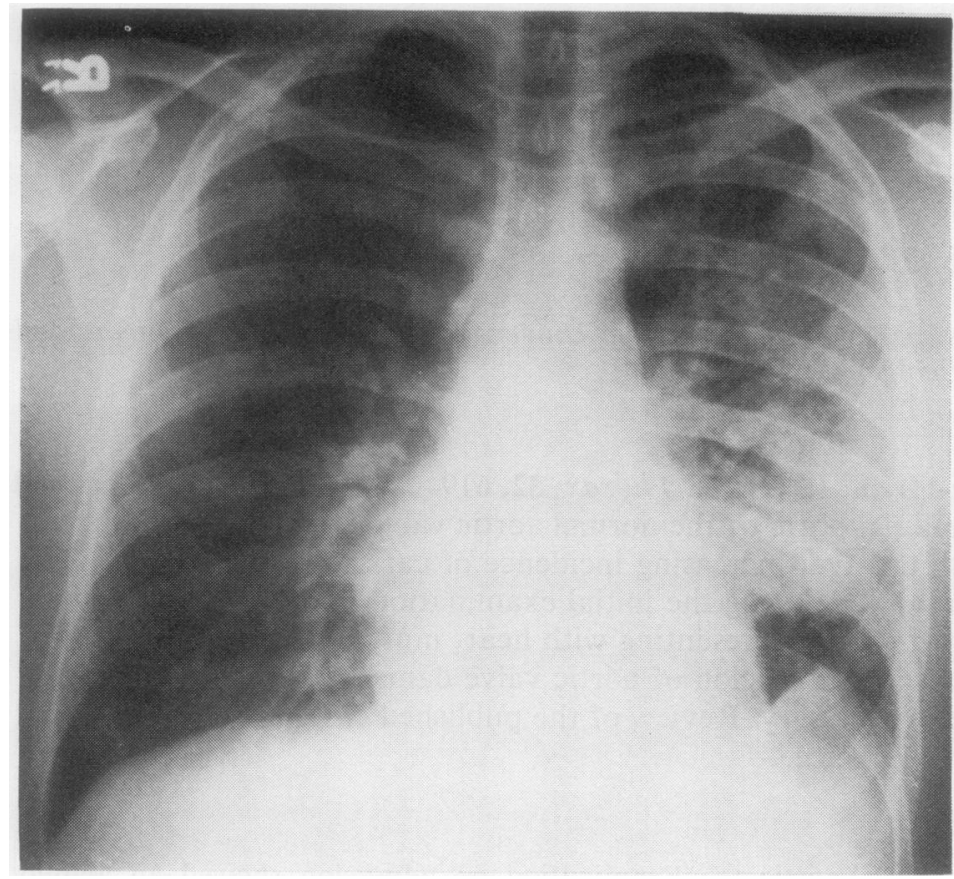

Fig. 1 Preoperative chest radiograph showing interstitial densities in the left lung.

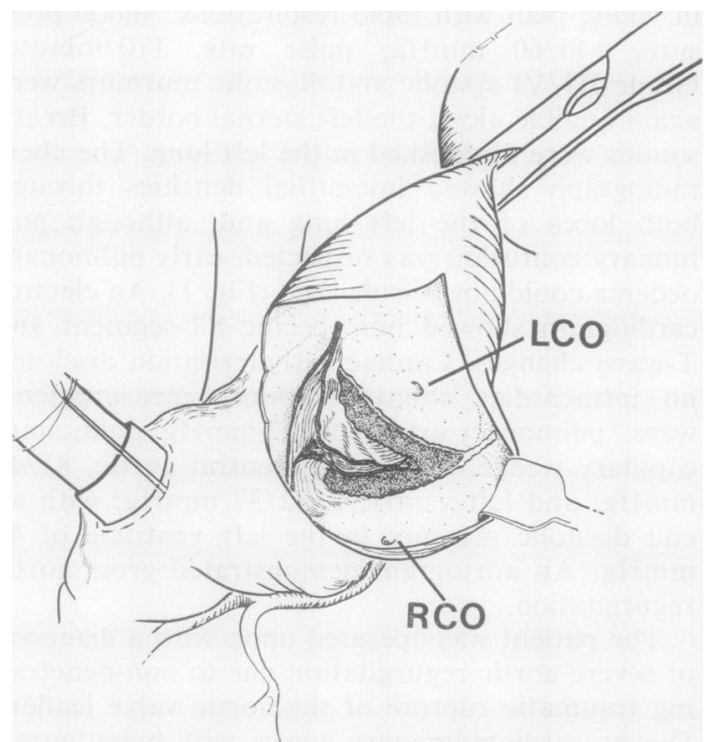

Fig. 2 Diagram representing the operative findings. Avulsion of left and right coronary cusps as well as avulsion of the intercoronary commissure: $L C O=$ left coronary ostium; $R C O=$ right coronary ostium.

serted. The patient's condition improved dramatically and he was discharged on 16 September 1975. He remains in excellent condition and his normal activities are not restricted.

\section{Discussion}

The mechanism of non-penetrating rupture of th aortic valve is believed to be a sudden increase of intrathoracic pressure at the time of impact, paf ticularly during early diastole when the pressure difference across the aortic valve is maximal.

Although Plenderleath in 1830 first reported case of rupture of an aortic valve, it was Boui laud in 1841 who first recorded injury to a normat aortic valve as a result of blunt, non-penetrating trauma. Howard (1928), reviewing the literature from 1830 to 1928 , gathered 44 proved cases of rupture of the aortic valve. Fourteen were a resule of chest trauma and 30 of muscular strain, a ratiQ of $1: 2$. Loop et al. (1971) have summarised the 15 documented cases between 1955 and 1970. The rupture was the result of trauma in 13, and in two the result of strain, a $6: 1$ ratio, reflecting oufs contemporary lifestyle. Parmley et al. (1958) re屯 viewed 546 necropsy cases of non-penetrating traumatic injury to the heart. Four instances aortic valve rupture $(0.73 \%)$ were found and onle one of these was not associated with a more sige nificant lethal cardiac injury.

Clinically, cardiac injury is often overlooked $a \frac{0}{\Phi}$ the initial post-trauma assessment due to the lack of a high index of suspicion on the part of the physician. Also, other more obvious multiple ino juries take precedence and mask the manifestas 
tions of cardiac trauma which, in most instances, must be searched for at this stage if they are not to be missed. The distressed and laboured breathing of the patient may prohibit thorough auscultation of the heart. Fractured ribs and pulmonary contusion are frequently blamed for the shortness of breath and chest pain. The diagnosis of aortic valve rupture is often delayed or missed for a time interval of days to months (Table).

In 1954 Leonard et al. (1955), who were the first to treat this injury surgically, inserted a Hufnagel valve in the descending aorta. Fourteen additional cases of surgical treatment of nonpenetrating traumatic rupture of the normal aortic valve have now been recorded (Table). Primary repair was undertaken in four patients. One of these died in the operating room, one other de- veloped severe aortic regurgitation necessitating valve replacement 21 months later, and the other two survived (one with mild-to-moderate regurgitation). The remaining 10 patients underwent valve replacement as the initial procedure, survived, and did well.

The avulsion-type valve injury most frequently seen after blunt chest trauma makes primary repair difficult and usually non-lasting so that valve replacement is the recommended operative procedure.

We conclude that any patient without a history of heart disease presenting with heart murmurs after severe blunt trauma to the chest should give rise to the suspicion of aortic valve damage. Recognition of the early signs is important so that proper clinical safeguards can be instituted to

Table Operated cases of nonpenetrating traumatic rupture of the normal aortic valve

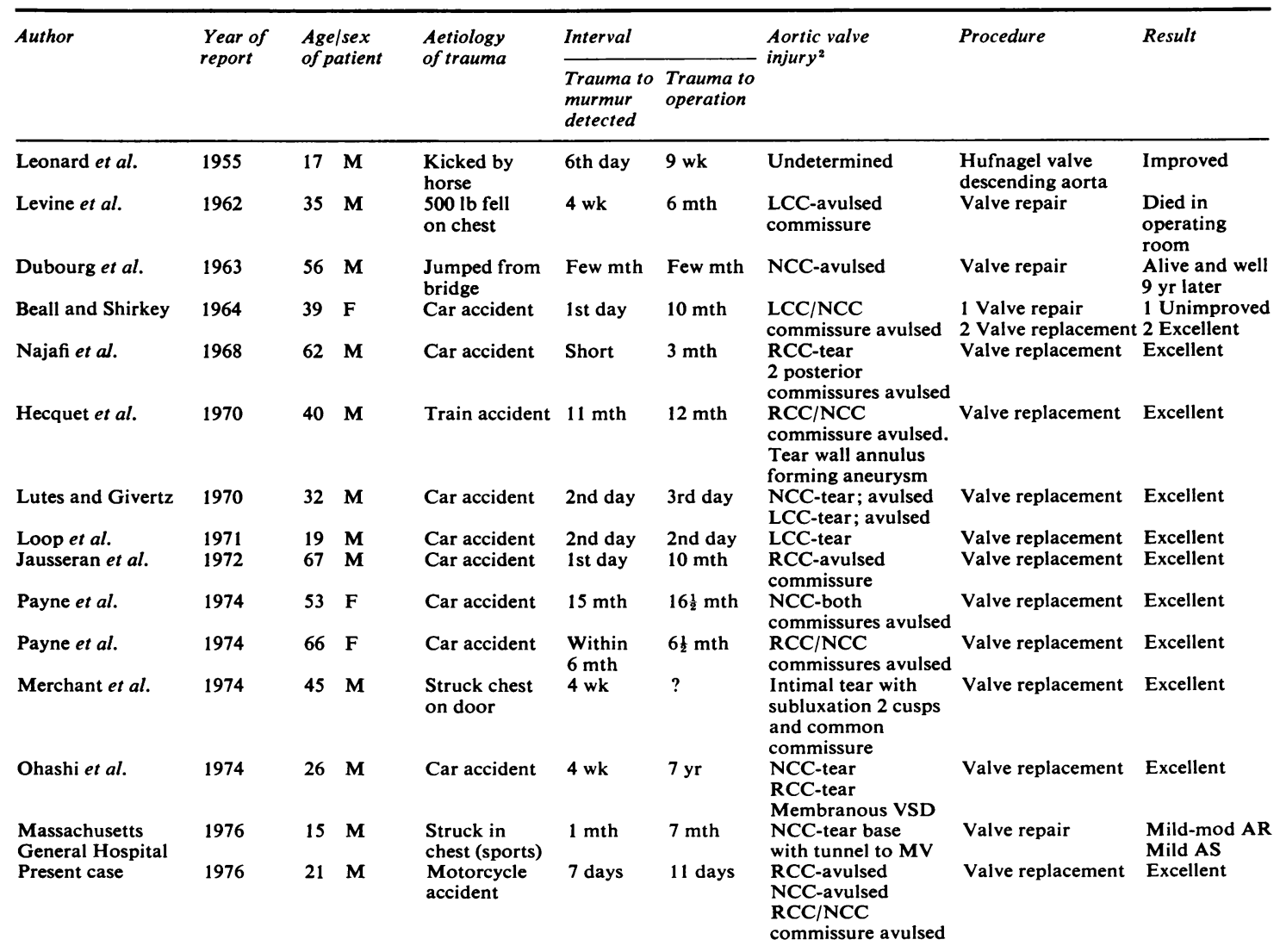

$\overline{L C C}=$ left coronary cusp; $\mathbf{N C C}=$ noncoronary cusp; $\mathbf{R C C}=$ right coronary cusp; $\mathrm{VSD}=$ ventricular septal defect $; \mathbf{M V}=$ mitral valve $; \mathbf{A R}=$ aortic regurgitation; and $\mathbf{A S}=$ aortic stenosis.

'Two additional reports are not included because of underlying cystic medial necrosis (Dimond et al., 1957; Cleveland and Cleveland, 1974).

'In an attempt to standardise terminology relating to the valve leaflet and to the type of injury, $R C C=$ anterior cusp; $L C C=$ left posterior cusp; $\mathrm{NCC}=$ right posterior cusp; tear = perforation; and avulsion $=$ detachment or rupture. 
minimise complications and to ensure appropriate treatment.

We express our appreciation to Mrs. Beverly Zell for her help in the preparation of this manuscript.

\section{References}

Beall, A. C., Jr., and Shirkey, A. L. (1964). Successful surgical correction of traumatic aortic valve regurgitation. Journal of the American Medical Association, 187, 507-510.

Bouillaud, J. B. (1841). Traité Clinique des Maladies $d u$ Coeur, 2nd edition, Vol. II, p. 626. Ballière, Paris.

Cleveland, J. C., and Cleveland, R. J. (1974). Successfull repair of aortic root and aortic valve injury caused by blunt chest trauma in a patient with prior aortic dissection. Chest, 66, 447-450.

Dimond, E. G., Larsen, W. E., Johnson, W. B., and Kittle, C. F. (1957). Post-traumatic aortic insufficiency occurring in Marfan's syndrome, with attempted repair with a plastic valve. New England Journal of Medicine, 256, 8-11.

Dubourg, G., Fontan. F., Trarieux, M., Galy, J. C., Ploquin, F., Dallochio, M., Bricaud, H., and Broustet, P. (1963). Insuffisance aortic traumatique: correction chirurgicale sous hypothermie profonde. Archives des Maladies du Coeur, 56, 782-790.

Hecquet, J. P., Nadiras, P., Petténati, G., Trebolle, R. and Muller, P. (1970). Insuffisance aortique traumatique par rupture d'une valve par ailleurs normale. Medecine Legale et Dommage Corporel, 4, 130-132.

Howard, C. P. (1928). Aortic insufficiency due to rupture by strain of a normal aortic valve. Canadian Medical Association Journal, 19, 12-24.

Jausseran, J. M., Baille, Y., Monties, J. R., Goudard. A., Anfossi, G., Donnarel. D., and Henry E. (1972). Rupture traumatique des sigmoides aortiques. A propos d'un cas opéré. Revue de la littérature chirurgicale. Annales de Chirurgie Thoracique Cardio-Vasculaire, 11, 355-359.

Leonard, J. J., Harvey, W. P.. and Hufnagel, C. A. (1955). Rupture of the aortic valve. A therapeutic approach. New England Journal of Medicine, 252, 208-212.

Levine, R. J., Roberts, W. C., and Morrow, A. G.C (1962). Traumatic aortic regurgitation. American Journal of Cardiology, 10, 752-763.

Loop, F. D., Hofmeier, G., and Groves, L. K. (1971). $\stackrel{\Phi}{\circ}$ Traumatic disruption of the aortic valve. Cleveland Clinic Quarterly, 38, 187-194.

Lutes, C. A., and Givertz, B. (1970). Traumatic $\vec{\circ}$ rupture of the normal aortic valve. Journal of the Maine Medical Association, 61, 183-185.

Massachusetts General Hospital (1976). Case records. Case 3-1976. New England Journal of Medicine,,$\vec{x}$ 294, 152-158.

Merchant, F., Harris, G., and Long, D. M. (1974). Traumatic subluxation of an aortic cusp. Journal of $\circ$ Cardiovascular Surgery (Torino), 15, 472-474.

Najafi, H., Dye, W. S., Javid, H., Hunter, J. A., ando Julian, O. C. (1968). Rupture of an otherwise normal aortic valve: report of two cases and review of the literature. Journal of Thoracic and Cardiovascular Surgery, 56, 57-62.

Ohashi, H., Kawashima, Y., Miyamoto, I., et al.Ф (1974). Rupture of aortic valve and ventricular septum due to non-penetrating trauma: a case report (Japanese). Journal of the Japanese Associa tion for Thoracic Surgery, 22, 1194-1199.

Parmley, L. F., Manion, W. C., and Mattingly, T. WS (1958). Nonpenetrating traumatic injury of the heart. Circulation, 18, 371-396.

Payne, D. D., DeWeese, J. A., Mahoney, E. B., anç Murphy, G. W. (1974). Surgical treatment of trau? matic rupture of the normal aortic valve. Annal. $\overrightarrow{\vec{B}}$ of Thoracic Surgery, 17, 223-229.

Plenderleath, D. (1830). Case of death from rupture of one of the semilunar valves of the aorta. London Medical Gazette, 7, 109-110.

Requests for reprints to: Professor L. Gonzalez-Lavin Professor and Chief, Division of Cardiothoracic Surô gery, Michigan State University, B437 Clinical Center? East Lansing, MI 48824, USA. 